\title{
Catalytic Oxidation of Sulfides to Sulfoxides by Poly(4-vinyl pyridinium nitrate), Silica Sulfuric Acid and Ammonium Bromide as a Catalyst
}

\author{
Arash GHORBANI-CHOGHAMARANI ${ }^{1, *}$, Sara SARDARI ${ }^{2}$ \\ ${ }^{1}$ Department of Chemistry, Faculty of Science, Ilam University, P.O. Box 69315516, Ilam, Iran \\ ${ }^{2}$ Islamic Azad University, Branch-Omidiyeh, Ahvaz, Iran
}

\begin{abstract}
A new catalytic procedure for the chemoselective oxidation of sulfides to sulfoxides was studied. A variety of aliphatic and aromatic sulfides were subjected to sulfoxidation by combining poly(4-vinyl pyridinium nitrate), silica sulfuric acid $\left(\mathrm{SiO}_{2}-\mathrm{OSO}_{3} \mathrm{H}\right)$, and catalytic amounts of ammonium bromide in $\mathrm{CH}_{2} \mathrm{Cl}_{2}$ in the presence of a few drops of water at room temperature. Excellent yields were obtained.
\end{abstract}

Key words: sulfoxide; sulfide; poly(4-vinyl pyridinium nitrate); ammonium bromide; silica sulfuric acid

CLC number: O643 Document code: A

Sulfoxides are useful for stereocontrol in asymmetric synthesis and they are important targets of pharmaceutical interest [1]. They have been used as reagents in transformations such as the oxidation of thiols [2,3], the 1,4-diacetoxylation of 1,3-diene [4], asymmetric alkylation [5], and the enantioselective synthesis of dihydroisoindol-4-ols [6]. Sulfoxides are generally prepared by the oxidation of their corresponding sulfides. However, it is often very difficult to stop the oxidation at the sulfoxide stage [7]. Many reagents and oxidizing media exist for the oxidation of sulfides [8-16]. However, most of them are not satisfactory because of the formation of environmentally unfriendly by-products, over-oxidation to sulfones, low product yields, tedious workup, toxicity, and reagent expense.

\section{Experimental}

All chemicals were purchased from Fluka, Merck, and Aldrich. The oxidation products were characterized by comparing their spectral (IR, ${ }^{1} \mathrm{H} \mathrm{NMR}$, and ${ }^{13} \mathrm{C} \mathrm{NMR}$ ) and physical data with authentic samples [8-22].

\subsection{Preparation of poly(4-vinyl pyridinium nitrate)}

In a $50-\mathrm{ml}$ round-bottomed flask, $2 \mathrm{ml}$ of $\mathrm{HNO}_{3}(65 \%)$ and $3.03 \mathrm{~g}$ of poly(4-vinylpyridine) was stirred for $1 \mathrm{~h}$ and then kept at $50{ }^{\circ} \mathrm{C}$ for $48 \mathrm{~h}$ to quantitatively obtain dry poly(4-vinyl pyridinium nitrate) as a white crystalline solid.

\subsection{Oxidation of 2-(phenylthio)ethanol (1g) to}

2-(phenyl sulfinyl)ethanol (2g) using poly(4-vinyl pyridinium nitrate) and silica sulfuric acid in the presence of a catalytic amount of ammonium bromide

In a typical procedure, silica sulfuric acid $(0.65 \mathrm{~g})$ and two drops of water were added to a suspension of $\mathrm{NH}_{4} \mathrm{Br}$ (0.005 g, $0.05 \mathrm{mmol})$, poly(4-vinyl pyridinium nitrate) $(0.672 \mathrm{~g})$, and 2-(phenylthio)ethanol $(0.154 \mathrm{~g}, 1 \mathrm{mmol})$ in dichloromethane. The resulting mixture was stirred at room temperature for $8 \mathrm{~h}$ (the reaction progress was monitored by TLC) and then filtered. The residue was washed with $\mathrm{CH}_{2} \mathrm{Cl}_{2}(20 \mathrm{ml})$. Anhydrous $\mathrm{Na}_{2} \mathrm{SO}_{4}(1.5 \mathrm{~g})$ was added to the filtrate and filtered off after $20 \mathrm{~min}$. Finally, $\mathrm{CH}_{2} \mathrm{Cl}_{2}$ was evaporated and 2-(phenylsulfinyl)ethanol (2g) was obtained as a colorless oil $(0.168 \mathrm{~g}, 99 \%) .{ }^{1} \mathrm{H}$ NMR (200 MHz, $\left.\mathrm{CD}_{3} \mathrm{SOCD}_{3}\right): \delta$ 7.51-7.94 (m, 5H), $5.89(\mathrm{~s}, 1 \mathrm{H}), 3.63-3.88$ $(\mathrm{m}, 2 \mathrm{H}), 2.83-3.01(\mathrm{~m}, 2 \mathrm{H}) ;{ }^{13} \mathrm{C} \mathrm{NMR}\left(50 \mathrm{MHz}, \mathrm{CD}_{3} \mathrm{SO}-\right.$ $\mathrm{CD}_{3}$ ): $\delta 144.9,132.1,131.1,123.6,60.4,55.8$ (Ref. [23]).

\section{Results and discussion}

Our recent work has focused on the in situ generation of the bromonium ion $\left(\mathrm{Br}^{+}\right)$and the nitronium ion $\left(\mathrm{NO}_{2}^{+}\right)$and their application to different organic reactions [17-27]. In continuation of this work we decided to explore catalytic and metal-free media for the in situ generation of $\mathrm{Br}^{+}$. We thus prepared poly(4-vinylpyridinium nitrate) by the reaction of poly(4-vinylpyridine) with nitric acid (Scheme 1).

We found that poly(4-vinyl pyridinium nitrate) is an oxidant in the presence of acids. Therefore we decided to in-

Received date: 25 May 2010.

*Corresponding author. Tel: +98-841-2227022; Fax: +98-841-2227022; E-mail: arashghch58@yahoo.com, a.ghorbani@mail.ilam.ac.ir Foundation item: Supported by the research facilities of Ilam University, Ilam, Iran.

English edition available online at ScienceDirect (http://www.sciencedirect.com/science/journal/18722067). 


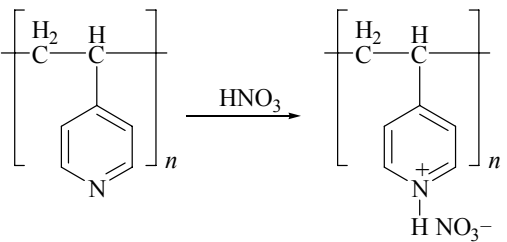

Scheme 1. Preparation of poly(4-vinyl pyridinium nitrate).

troduce poly(4-vinyl pyridinium nitrate) as a novel oxidizing polymer for the conversion of sulfides to sulfoxides in the presence of silica sulfuric acid $\left(\mathrm{SiO}_{2}-\mathrm{OSO}_{3} \mathrm{H}\right)$ and catalytic amounts of ammonium bromide.

Initially, to find an appropriate solvent for this transformation we screened different solvents for the oxidation of dibenzyl sulfide as a typical example. The results are summarized in Table 1. As is evident from Table 1, the oxidation reaction proceeds more rapidly and selectively in dichloro-
Table 1 Oxidation of dibenzyl sulfide by poly(4-vinyl pyridinium nitrate), silica sulfuric acid, and catalytic amounts of $\mathrm{NH}_{4} \mathrm{Br}$ in different solvents at room temperature

\begin{tabular}{lcc}
\hline Solvent & Time (min) & Yield $^{\mathrm{a}}(\%)$ \\
\hline Acetonitrile & 22 & 98 \\
Acetone & 1440 & $-{ }^{\mathrm{b}}$ \\
Chloroform & 1440 & 98 \\
Dichloromethane & 15 & 97 \\
$n$-Hexane & 1440 & $-{ }^{\mathrm{b}}$ \\
Ethanol & 1440 & $-{ }^{\mathrm{b}}$ \\
Ethyl acetate & 1800 & $88^{\mathrm{c}}$ \\
\hline
\end{tabular}

Reaction conditions: substrate $1 \mathrm{mmol}$, poly(4-vinyl pyridinium nitrate) $0.336 \mathrm{~g}, \mathrm{NH}_{4} \mathrm{Br} 0.05 \mathrm{mmol}$, silica sulfuric acid $0.3 \mathrm{~g}$, two drops of water. ${ }^{a}$ Isolated yield. ${ }^{b}$ No reaction. ${ }^{c}$ Sulfoxide purified by TLC.

methane.

With optimal conditions in hand, we report on the

Table 2 Oxidation of sulfides 1 to their corresponding sulfoxides 2

\begin{tabular}{|c|c|c|c|c|c|c|c|c|c|}
\hline \multirow{2}{*}{ Entry } & \multirow{2}{*}{\multicolumn{2}{|c|}{ Substrate }} & \multirow{2}{*}{ Product } & \multicolumn{3}{|c|}{ Amount } & \multirow{2}{*}{ Time (min) } & \multirow{2}{*}{ Yield $^{\mathrm{a}}(\%)$} & \multirow{2}{*}{ TON } \\
\hline & & & & I (g) & II (g) & III (mmol) & & & \\
\hline 1 & $1 \mathrm{a}$ & & $2 a$ & 0.336 & 0.3 & 0.05 & 17 & 83 & 16.6 \\
\hline 2 & $1 b$ & & $2 b$ & 0.336 & 0.3 & 0.05 & 45 & 92 & 18.4 \\
\hline 3 & $1 \mathrm{c}$ & & $2 c$ & 0.336 & 0.3 & 0.05 & 20 & 88 & 17.6 \\
\hline 4 & $1 d$ & & $2 d$ & 0.336 & 0.3 & 0.05 & 50 & 98 & 19.6 \\
\hline 5 & $1 \mathrm{e}$ & & $2 \mathrm{e}$ & 0.336 & 0.3 & 0.05 & 26 & 87 & 17.4 \\
\hline 6 & $1 e$ & & $2 \mathrm{e}$ & 0.336 & 0.3 & - & 1440 & $-^{b, c}$ & - \\
\hline 7 & $1 e$ & & $2 e$ & 0.336 & - & 0.05 & 1440 & $\complement^{\mathrm{c}, \mathrm{d}}$ & - \\
\hline 8 & 1f & & $2 f$ & 0.336 & 0.3 & 0.05 & 15 & 97 & 19.4 \\
\hline 9 & $1 \mathrm{~g}$ & & $2 g$ & 0.670 & 0.65 & 0.20 & 480 & 99 & 4.95 \\
\hline 10 & $1 \mathrm{~h}$ & & $2 \mathrm{~h}$ & 0.336 & 0.3 & 0.05 & 20 & 99 & 19.8 \\
\hline 11 & $1 \mathbf{i}$ & & $2 \mathbf{i}$ & 0.504 & 0.5 & 0.20 & 4200 & 97 & 4.85 \\
\hline 12 & $1 \mathbf{j}$ & & $2 j$ & 0.336 & 0.3 & 0.05 & 140 & 98 & 19.6 \\
\hline 13 & $1 \mathrm{k}$ & & $2 k$ & 0.336 & 0.3 & 0.05 & 23 & 98 & 19.6 \\
\hline 14 & 11 & & 21 & 0.336 & 0.3 & 0.05 & 30 & 90 & 18.0 \\
\hline 15 & $1 \mathrm{~m}$ & $\mathrm{C}_{11} \mathrm{H}_{2}$ & $2 m$ & 0.336 & 0.3 & 0.05 & 15 & 96 & 19.2 \\
\hline 16 & 1n & & $2 n$ & 0.336 & 0.3 & 0.05 & 25 & 95 & 19.0 \\
\hline 17 & 10 & & 20 & 0.336 & 0.3 & 0.05 & 35 & 60 & 12.0 \\
\hline
\end{tabular}

Other conditions: two drops of water, dichloromethane as solvent, room temperature. ${ }^{\mathrm{a}}$ Isolated yield. ${ }^{\mathrm{b}}$ In the absence of $\mathrm{NH}_{4} \mathrm{Br}$. ${ }^{\mathrm{c}} \mathrm{Reaction}$ not complete. ${ }^{\mathrm{d}}$ In the absence of silica sulfuric acid. 
chemoselective oxidation of a variety of aliphatic and aromatic sulfides $\mathbf{1}$ to their corresponding sulfoxides $\mathbf{2}$ by poly(4-vinyl pyridinium nitrate) $\mathbf{I}$, silica sulfuric acid $\left(\mathrm{SiO}_{2}-\mathrm{OSO}_{3} \mathrm{H}\right)$ II, and a catalytic amount of ammonium bromide III in the presence of two drops of water in dichloromethane at room temperature with good to excellent yields (Table 2).

Sulfoxides were heterogeneously prepared under mild conditions. Pure products were obtained easily by mixing a sulfide, poly(4-vinyl pyridinium nitrate), silica sulfuric acid, and catalytic amounts of $\mathrm{NH}_{4} \mathrm{Br}$ in the presence of water (2 drops) in $\mathrm{CH}_{2} \mathrm{Cl}_{2}$ as solvent. This mixture was stirred at room temperature. Eventually, the pure product was easily obtained by simple filtration and evaporation of the reaction solvent.

As is evident from Table 2, a good turn over number (TON) range for the catalyst was obtained. To determine the role of ammonium bromide as catalyst, ethyl phenyl sulfide (as a typical example) was selected for the oxidation reaction in the absence of $\mathrm{NH}_{4} \mathrm{Br}$. Interestingly, the reaction was not complete after $24 \mathrm{~h}$ (Table 2, entry 6). We also observed that the sulfoxidation reaction of ethyl phenyl sulfide was not complete in the absence of silica sulfuric acid after $24 \mathrm{~h}$ (Table 2, entry 7), which means that the presence of acid is necessary for this reaction.

Entry 12 from Table 2 shows that this catalytic media homoselectively oxidized thiantrene to thianthrene monosulfoxide. This result is in close agreement with our previous report on the oxidation of sulfides to sulfoxides [17-22]. A ${ }^{13} \mathrm{C}$ NMR of the oxidation product (thianthrene monosulfoxide) shows six peaks at $\delta=141.2,130.9,129.8$, 129.4, 128.2, and 124.7.

It is of interest to note that the described system allows

Table 3. Oxidation of benzyl phenyl sulfide with poly(4-vinyl pyridinium nitrate), the solid acid, two drops of water, and catalytic amounts of $\mathrm{NH}_{4} \mathrm{Br}$ in dichloromethane at room temperature

\begin{tabular}{lcc} 
Solid acid & Time (min) & Yield $^{\mathrm{a}}(\%)$ \\
\hline $\mathrm{Zn}\left(\mathrm{HSO}_{4}\right)_{2}$ & 170 & 90 \\
$\mathrm{Zr}\left(\mathrm{HSO}_{4}\right)_{4}$ & 35 & 99 \\
$\mathrm{Ca}\left(\mathrm{HSO}_{4}\right)_{2}$ & 265 & 98 \\
$\mathrm{KHSO}_{4}$ & 1380 & $-{ }^{\mathrm{b}}$ \\
$\mathrm{Fe}\left(\mathrm{HSO}_{4}\right)_{2}$ & 4320 & $-^{\mathrm{c}}$ \\
$\mathrm{Al}\left(\mathrm{HSO}_{4}\right)_{3}$ & 30 & 97 \\
$\mathrm{~L}-\mathrm{Alanine}^{\mathrm{d}}$ & 1500 & ${ }^{\mathrm{d}}$ \\
$\mathrm{NH}_{2} \mathrm{SO}_{3} \mathrm{H}$ & 1500 & d $^{\mathrm{d}}$ \\
$\mathrm{Citric}$ acid & 1500 & ${ }^{\mathrm{d}}$
\end{tabular}

Substrate $1 \mathrm{mmol}$, poly(4-vinyl pyridinium nitrate) $0.336 \mathrm{~g}$, solid acid 2 mmol, $\mathrm{NH}_{4} \mathrm{Br} 0.05$ mmol. ${ }^{\mathrm{a}}$ Isolated yield. ${ }^{\mathrm{b}}$ Reaction not complete. ${ }^{\mathrm{c}}$ Trace conversion. ${ }^{\mathrm{d}}$ No reaction.

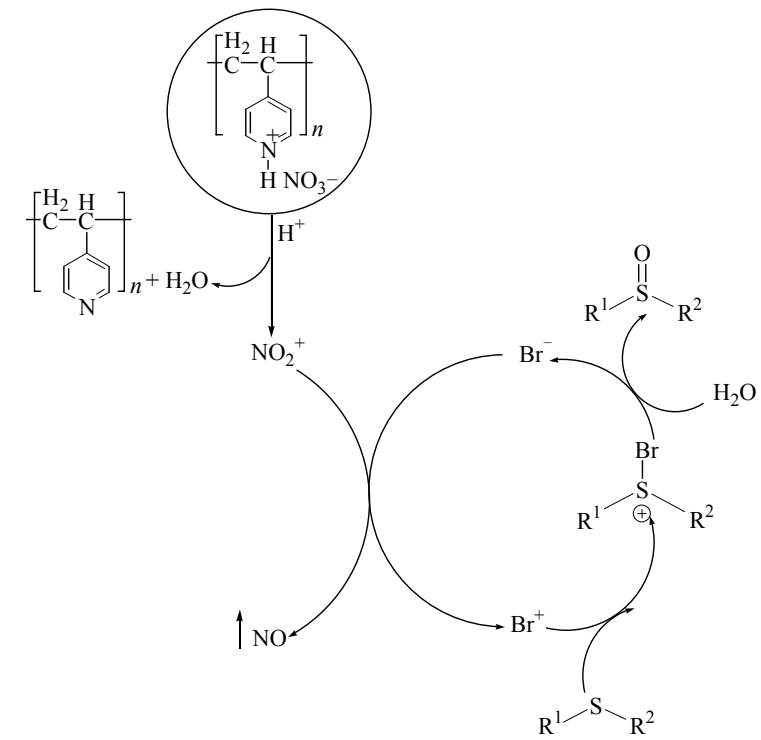

Scheme 2. Mechanism of the sulfoxidation reaction of sulfides.

for the chemoselective oxidation of 2-(phenylthio)ethanol (1g) to 2-(phenylsulfinyl)ethanol (2g) and the hydroxyl group remains intact during the course of the reaction (Table 2 , entry 9).

To investigate and develop the scope and limitations of this oxidizing media we decided to examine different solid acids in place of silica sulfuric acid. These reactions were carried out by mixing benzyl phenyl sulfide (1 mmol), poly(4-vinyl pyridinium nitrate) $(0.336 \mathrm{~g})$, the acid (2 $\mathrm{mmol})$, and $\mathrm{NH}_{4} \mathrm{Br}(5 \mathrm{~mol} \%)$ in the presence of water (2 drops) and in $\mathrm{CH}_{2} \mathrm{Cl}_{2}$ (Table 3). As shown in Table 3, a variety of solid acids are capable of this transformation in addition to silica sulfuric acid.

A plausible mechanism for the described transformation is outlined in Scheme 2.

\section{Conclusions}

A novel catalytic procedure for the selective oxidation of sulfides to sulfoxides under metal-free, mild, and heterogeneous conditions was investigated. The advantages of this method are no environmental pollution, shorter reaction times, high selectivity, non-toxic conditions, cost effective reagents and catalyst, and easy workup.

\section{References}

1 Russo A, Lattanzi A. Adv Synth Catal, 2009, 351: 521

2 Lowe O G. J Org Chem, 1975, 40: 2096

3 Abu-Omar M M, Khan S I. Inorg Chem, 1998, 37: 4979

4 Grennberg H, Gogoll A, Backvall J E. J Org Chem, 1991, 56: 5808

5 Fernandez I, Araujo C S, Alcudia F, Khiar N. Phosphorus 
Sulfur Silicon Relat Elem, 2005, 180: 1509

6 Hashmi A S K, Schafer S, Bats J W, Frey W, Rominger F. Eur J Org Chem, 2008, 2008: 4891

7 Kirihara M, Yamamoto J, Noguchi T, Hirai Y. Tetrahedron Lett, 2009, 50: 1180

8 Yang C B, Jin Q P, Zhang H, Liao J, Zhu J, Yu B, Deng J E. Green Chem, 2009, 11: 1401

9 Jayaseeli A M I, Rajagopal S. J Mol Catal A, 2009, 309: 103

10 Dilsha K M, Kothari S. J Chem Sci, 2009, 121: 189

11 Dhakshinamoorthy A, Pitchumani K. Catal Commun, 2009, 10: 872

12 Jiang B, Zhao X L, Dong J J, Wang W J. Eur J Org Chem, 2009, 2009: 987

13 Shi X-Y, Wei J-F. J Mol Catal A, 2008, 280: 142

14 Shi F, Tse M K, Kaiser H M, Beller M. Adv Synth Catal, 2007, 349: 2425

15 Hosseinpoor F, Golchoubian H. Tetrahedron Lett, 2006, 47: 5195

16 Mirkhani V, Tangestaninejad S, Moghadam M, Mohammadpoor-Baltork I, Kargar H. J Mol Catal A, 2005, 242: 251

17 Ghorbani-Choghamarani A, Goudarziafshar H, Nikoorazm M,
Yousefi S. Lett Org Chem, 2009, 6: 335

18 Ghorbani-Choghamarani A, Rezaei S. J Chin Chem Soc, 2009, 56: 251

19 Habibi D, Zolfigol M A, Safaiee M, Shamsian A, Ghorbani-Choghamarani A. Catal Commun, 2009, 10: 1257

20 Amani K, Zolfigol M A, Ghorbani-Choghamarani A, Hajjami M. Monatsh Chem, 2009, 140: 65

21 Zolfigol M A, Amani K, Hajjami M, Ghorbani-Choghamarani A. Monatsh Chem, 2008, 139: 895

22 Zolfigol M A, Amani K, Ghorbani-Choghamarani A, Hajjami M, Ayazi-Nasrabadi R, Jafari S. Catal Commun, 2008, 9: 1739

23 Lakouraj M M, Tajbakhsh M, Shirini F, Tamami M V A. Synth Commun, 2005, 35: 775

24 Ghorbani-Choghamarani A, Chenani Z, Mallakpour S. Synth Commun, 2009, 39: 4264

25 Ghorbani-Choghamarani A, Goudarziafshar H, Nikoorazm M, Yousefi S. Can J Chem, 2009, 87: 1144

26 Ghorbani-Choghamarani A, Nikoorazm M, Goudarziafshar H, Tahmasbi H. Bull Korean Chem Soc, 2009, 30: 1388

27 Ghorbani-Choghamarani A, Shiri L, Zeinivand J. Bull Korean Chem Soc, 2008, 29: 2496 